\title{
Características morfológicas encontradas na cavidade oral de neonatos: revisão de literatura
}

\author{
Morphological characteristics found in the oral cavity of newborns: \\ a literature review
}

Dayane Franco Barros Mangueira Leite* Carla Alves Vieira**

\section{Resumo}

Objetivo: revisar a literatura sobre as características morfológicas da cavidade oral de recém-nascidos. Revisão de literatura: as profissões da área de saúde estão cada vez mais voltadas para um acompanhamento precoce do indivíduo, iniciando-se antes mesmo do nascimento ou nos primeiros dias de vida da criança. Sendo assim, recém-nascidos apresentam na cavidade oral características peculiares da sua fase de desenvolvimento que podem trazer dúvidas para os pais e/ou responsáveis. As principais variações da cavidade oral de recém-nascidos envolvem tecidos duros e tecidos moles. Considerando o posicionamento dos maxilares, as alterações mais comuns são: mordida aberta anterior, sobremordida e mordida topo a topo. Em relação aos tecidos moles, o contorno dos lábios dos recém-nascidos se apresenta triangular e, com a amamentação constante, forma-se um aumento de volume na linha média do lábio superior. Considerações finais: além de ser necessário que os profissionais da área tenham conhecimento das características morfológicas da cavidade oral dos recém-nascidos, também é imprescindível que estes saibam diagnosticar possíveis anormalidades e, quando houver necessidade, indicar tratamento adequado.

Palavras-chave: Manifestações bucais. Odontopediatria. Recém-nascido.

\section{Introdução}

As profissões da área da saúde estão cada vez mais voltadas para um acompanhamento precoce do indivíduo, visando à prevenção de doenças e à promoção de saúde. Com a odontologia, especialmente a odontopediatria, essa situação não é diferente. Muitas vezes, os cuidados começam antes mesmo do primeiro ano de vida da criança ${ }^{1-3}$. É comum que crianças com poucos dias ou com meses de vida sejam levadas ao consultório odontológico para que os pais e/ou responsáveis recebam instruções educativas para a investigação ou o tratamento de alguma anomalia ou alteração ${ }^{2}$.

Muitos aspectos da cavidade oral de um bebê são únicos e peculiares a esse período de vida. Na infância, a boca apresenta desenvolvimento constante, estando em relação dinâmica com outros sistemas e órgãos, que também estão em desenvolvimento. Por isso, ela apresenta estruturas anatômicas únicas, transitórias e características desse período da vida. Assim como os processos fisiológicos são típicos, também existem alterações de desenvolvimento e patologias próprias dessa faixa etária ${ }^{4}$. Então, uma variedade de alterações pode ocorrer na cavidade bucal dos bebês, como os dentes natais ou neonatais, os cistos ou hematomas de erupção, dentre outras ${ }^{4,5}$. 
Nessa perspectiva, é necessário que o cirurgião-dentista não só tenha conhecimento das características morfológicas da cavidade oral dos recém-nascidos, como também é imprescindível que saibam identificar e diagnosticar possíveis alterações da normalidade, que, muitas vezes, podem ser consideradas normais para a fase de desenvolvimento da criança. Assim, eles poderão esclarecer, tranquilizar e orientar os pais e estabelecer o tratamento adequado, quando necessário.

Desse modo, este trabalho teve como objetivo revisar a literatura sobre as principais características morfológicas da cavidade oral de recém-nascidos com o intuito de orientar os profissionais a conhecer estas características e reconhecer qualquer padrão fora da normalidade.

\section{Método}

A presente pesquisa bibliográfica foi desenvolvida por meio da análise documental da produção bibliográfica disponível nas bases de dados BBO, Lilacs e Medline, vinculadas à biblioteca virtual Bireme (http://www.bireme.br), e em livros disponíveis na Biblioteca Setorial do Centro de Ciências da Saúde e na Biblioteca Central da Universidade Federal da Paraíba. Foram usadas as palavras de busca nos idiomas português e inglês: Odontopediatria/Pediatric Dentistry, Recém-nascido/Newborn, Manifestações bucais/Oral manifestations.

\section{Revisão de literatura}

A face do indivíduo pode ser considerada como sua janela para o mundo, tendo em vista que estruturas anatômicas responsáveis por três dos cinco sentidos humanos estão na face: os olhos, responsáveis pela visão, o nariz, responsável pelo olfato, e a boca, responsável pelo paladar. Essas estruturas formam-se entre a oitava e a décima semanas de vida intrauterina e começam a desenvolver suas funções ainda nessa fase. Podemos afirmar que, quando o indivíduo nasce, a cavidade bucal é um sistema muito ativo, pois é por meio dela que o bebê estabelece os seus primeiros vínculos com o mundo ${ }^{6}$.

A maxila e a mandíbula do recém-nascido são pequenas quando comparadas com as outras estruturas ósseas da cabeça ${ }^{2}$. A maxila apresenta-se com formato arredondado, pouco profunda e com as rugosidades palatinas bem pronunciadas, enquanto a mandíbula, por sua vez, apresenta-se em forma de "U"?.

Os neonatos apresentam cavidade oral edentada e formada pelos processos alveolares recobertos de mucosa de cor rosada e firmemente aderida, sendo denominados rodetes gengivais ${ }^{2}$. Os rodetes gengivais se segmentam para indicar os locais de desenvolvimento dos dentes ${ }^{8}$. Outra característica encontrada frequentemente é a presença de um cordão fibroso e flácido sobre a região de incisivos e caninos superiores e inferiores, conhecido como cordão fibroso de Robin e Magitot, que auxilia durante a sucção vedando os maxilares, mas desaparece quando os dentes decíduos começam a entrar em erupção $0^{2}$.

A relação intermaxilar pode acontecer de três maneiras: espaço ou abertura entre os rodetes da região anterior, equivalente à mordida aberta anterior, sobremordida e relação anterior topo a topo. Outra característica comum e natural em relação aos rodetes gengivais é a prevalência de um espaço vertical anterior, onde repousaria a língua ${ }^{2,7}$. De acordo com estudos realizados por Schmitt et al. ${ }^{3}$ (2012), 25,2\% dos bebês examinados apresentavam sobremordida e $16 \%$ apresentavam mordida aberta anterior.

Após o nascimento, a amamentação vai permitir ao bebê o exercício necessário para o desenvolvimento ósseo do sistema estomatognático, permitindo a obtenção de uma oclusão dentária normal e a consequente instalação de uma mastigação futura correta $^{9}$. Anteriormente, as superfícies vestibulares dos rodetes maxilar e mandibular apresentam proeminências provocadas pela presença das coroas dos dentes decíduos ainda não erupcionados. Na região dos caninos, essas proeminências estão mais evidentes ${ }^{2}$.

O contorno dos lábios do recém-nascido é caracteristicamente triangular, sendo à base do triângulo o lábio inferior e seu vértice o lábio superior. Com a amamentação constante após o nascimento, forma-se uma proeminência na linha média do lábio superior, denominada calo de amamentação (sucking pad callus). Essa proeminência fortalece o envolvimento da boca do bebê com o seio materno durante a amamentação ${ }^{7}$.

$\mathrm{Na}$ cavidade oral dos recém-nascidos, pode-se notar a presença de freios e bridas inseridos nos rebordos gengivais, que vão auxiliar na sucção do leite materno durante a amamentação. $\mathrm{O}$ freio labial superior é o que mais se destaca pelo seu volume e pela inserção ${ }^{10}$. No recém-nascido, o freio labial superior está firmemente aderido ao rebordo, estendendo-se até a papila palatina, recebendo o nome de freio teto labial ${ }^{11}$. Com a erupção dos incisivos e o desenvolvimento do osso alveolar, o freio labial desloca-se apicalmente, de maneira progressiva, para a superfície vestibular do rebordo alveolar, assumindo uma posição mais alta ${ }^{2,11}$. Caso o freio se mantenha na sua posição original, será denominado freio labial persistente, que é uma condição patológica. Suas fibras vão se estabelecer entre os dois incisivos centrais, podendo ocasionar o diastema interincisivos ${ }^{2,11}$.

Outra anomalia que pode ser encontrada é o freio lingual curto. O freio lingual é uma prega mediana de túnica mucosa que conecta a língua ao assoalho bucal, permitindo o movimento livre da língua ${ }^{12}$. Quando esse freio lingual se encontra 
curto no recém-nascido, a inserção do freio acontece na ponta da língua até o rebordo alveolar lingual, resultando na limitação dos movimentos da língua, podendo causar dificuldades na sucção, na deglutição e, posteriormente, na fala e na mastigação ${ }^{12}$. Essa anomalia do desenvolvimento é conhecida como anquiloglossia ${ }^{12,13}$.

Em bebês, quando os casos de freio teto labial persistente ou anquiloglossia dificultam ou impedem o bom selamento labial durante a amamentação, é recomendada a frenectomia ${ }^{2}$.

A partir da sexta semana de vida intrauterina, quando ocorre a proliferação do epitélio que originará o órgão dental, inicia-se o desenvolvimento dos dentes decíduos. A mineralização ocorre nesse período, e, ao nascimento, os dentes decíduos estão em diferentes fases de desenvolvimento, estando 3/5 do esmalte coronário dos incisivos inferiores já formados ${ }^{14}$. Os incisivos centrais inferiores são os primeiros dentes a irromper na cavidade oral, por volta dos seis meses de vida da criança ${ }^{15}$. Porém, têm sido relatados na literatura casos de crianças que já nascem com dentes erupcionados na cavidade oral, chamados de dentes natais, ou que erupcionam no primeiro mês de vida, denominados dentes neonatais ${ }^{16}$.

A prevalência dos dentes natais e neonatais varia entre 1:800 a 1:3.000, dependendo da população estudada e da metodologia aplicada ${ }^{15}$. Os incisivos centrais inferiores são os dentes mais acometidos por essas anomalias, devido ao fato de estes serem os primeiros dentes a erupcionar na cavidade oral da criança ${ }^{16}$.

\section{Discussão}

Apesar de a cavidade oral do recém-nascido saudável parecer simples, ela abarca processos variados e complexos ${ }^{17}$. Os músculos que integram o sistema estomatognático começam sua formação e maturação em torno da sexta semana de vida intrauterira $^{18}$, pois, ao nascimento, a boca e a musculatura associada à região orofacial devem estar em plena atividade para que as funções vitais do bebê, como respiração e deglutição, possam ser realiza$\operatorname{das}^{19}$.

Em relação ao crânio do recém-nascido, lateralmente, observa-se uma posição mais anterior da maxila em relação à mandíbula ${ }^{2} ; 97,3 \%$ das crianças avaliadas em estudo apresentavam essa característica $^{20}$. Corroborando esse padrão, 95,7\% das crianças apresentaram projeção maxilar, 4,3\% apresentaram relação topo a topo e nenhuma criança apresentou mandíbula anteriorizada ${ }^{21}$. Resultado semelhante foi observado em um estudo que avaliou 1.021 recém-nascidos, no qual a projeção da maxila foi observada em 99\% dos casos ${ }^{22}$. Acredita-se que essa posição mais distal da mandíbula é proveniente da posição ventral do feto na cavidade amniótica e que a inter-relação correta dos rebordos gengivais está relacionada com o reflexo da deglutição, logo, só ocorre após o nascimento ${ }^{8}$.

Como já mencionado, a cavidade oral de recém-nascidos é formada pelos processos alveolares recobertos de mucosas de cor rosada e aderida, denominada rodete gengival ou rebordo ${ }^{2}$. Um estudo envolvendo bebês com até seis dias de vida relatou algumas diferenças morfológicas no segmento anterior dos rodetes gengivais, sendo que o superior apresentou maiores variações ${ }^{21}$. Em $47,1 \%$ dos casos o rebordo superior apresentou-se firmemente aderido, liso e arredondado na região anterior, enquanto $52,9 \%$ dos bebês apresentaram rebordos irregulares e flácidos à palpação.

A inserção do freio labial é outra característica que pode variar nos recém-nascidos ${ }^{2}$. É mais frequente que o freio lingual se insira na crista do rebordo alveolar, mas pode ocorrer o freio teto labial persistente, que é uma condição patológica na qual o freio labial mantém-se inserido na papila, deixando que as fibras se estabeleçam entre os incisivos e podendo causar o diastema ${ }^{2,11}$. Em um estudo que procurou determinar a prevalência do freio teto labial persistente demonstrou que ele decresce com a idade, sendo encontrado em 53,8\% das crianças com até 6 meses; em 46,9\%, com 7 a 18 meses; em $16,5 \%$, com 19 a 30 meses; e em 15,2\%, com 31 a 36 meses de vida ${ }^{23}$.

No estudo de Schmitt et al. ${ }^{3}$ (2012), 11,3\% dos prontuários dos bebês que foram analisados apresentavam alterações no freio labial superior, sendo as mais comuns freio labial curto e freio teto labial persistente. Em relação à anquiloglossia, ou freio lingual curto, ao analisar 2.258 recém-nascidos, foi encontrada uma prevalência de $1,72 \%$ mais comum em meninos, em uma proporção de $3: 1^{24}$.

\section{Considerações finais}

A morfologia da cavidade oral dos recém-nascidos apresenta características próprias da sua fisiologia e de seu estágio de desenvolvimento. Portanto, é necessário que o cirurgião-dentista conheça os aspectos morfológicos normais e saiba identificar e diagnosticar precocemente possíveis variações da normalidade e anomalias mais comuns nessa fase de desenvolvimento. Assim, esse profissional estará apto a esclarecer e tranquilizar os pais, além de indicar a melhor conduta e o tratamento mais adequado, quando necessário. 


\section{Abstract}

Objective: to review the literature on the morphological characteristics of the oral cavity of newborns. Literature review: health professions are increasingly focused on the early follow-up of individuals, starting even before birth or during the first days of life of the child. Therefore, the oral cavity of newborns presents characteristics particular to their development phase, which may cause doubts to parents and/or caregivers. The major variations of the oral cavity of newborns involve both hard and soft tissues. Considering the positioning of the jaws, the most common changes are anterior open bite, overbite, and edge-to-edge bite. Regarding the soft tissues, the contour of the lips of newborns is triangular and constant breastfeeding causes an increase of volume formed in the midline of the upper lip. Final considerations: therefore, health professionals are required not only to understand the morphological characteristics of the oral cavity of newborns, but it is also essential that they are able to diagnose potential abnormalities and to indicate appropriate treatment when necessary.

Keywords: Oral manifestations. Pediatric dentistry. Newborn.

\section{Referências}

1. Guimarães AO, Costa ICC, Oliveira ALS. As origens, objetivos e razões de ser da odontologia para bebês. J Bras Odontopediatr Odontol Bebê 2003; 6(29):83-6.

2. Villena RS, Corrêa MSNP. Características do sistema estomatognático no recém-nascido e anomalias mais frequentes. In: Corrêa, MSNP. Odontopediatria na primeira infância. São Paulo: Santos, 2010; p. 113-26.

3. Schmitt BHE, Guzzi SH, Damo MN, Araujo SM, Farias MMAG. Características da cavidade oral de bebês recém-nascidos, Blumenau/SC. Pesq Bras Odontoped Clin Integr 2012; 12(1):89-92.

4. Baldani MH, Lopes CML, Scheidt WA. Prevalência de alterações bucais em crianças atendidas nas clínicas de bebês públicas de Ponta Grossa - PR, Brasil. Pesqui Odontol Bras 2001; 15(4):302-7.

5. Martínez HP, Aguilar FEG, Gutiérrez RJF. Lesiones orales del recién nacido. Oral 2015; 16(52):1283-6.

6. Corrêa MSNP, Machado MAAM, Rios D, Silva SMB, Oliveira TM. A Importância da boca da gestação à adolescência. In: Corrêa MSNP. Conduta clínica e psicológica na odontopediatria. São Paulo: Santos; 2013.

7. Abanto J, Raggio DP, Alves FBT, Corrêa FNP, Bönecker M, Corrêa MSNP. Oral characteristics of newborns: report of some oral anomalies and their treatment. Int J Dent 2009; 8(3):140-5.

8. Guedes-Pinto AC. Odontopediatria. São Paulo: Santos; 2006.

9. Bervian J, Fontana M, Caus B. Relação entre amamentação, desenvolvimento motor bucal e hábitos bucais: revisão de literatura. RFO UPF 2008; 13(2):76-81.

10. Camargo MCF, Bausells J. Atendimento longitudinal e continuado na clínica odontopediátrica. In: Bausells J. Odontopediatria: procedimentos clínicos. São Paulo: Premier; 1997. p. $75-89$.
11. Cavalcante JA, Xavier P, Mello-Moura ACV, Alencar CJF, Imparato JCP. Diagnóstico e tratamento cirúrgico do freio teto labial persistente em pacientes no período intertransitório da dentição mista - relato de caso. Rev Inst Ciênc Saúde 2009; 27(3):290-4.

12. Melo NSFO, Lima AAS, Fernandes A, Silva RPGVC. Anquiloglossia: relato de caso. RSBO 2011; 8(1):102-7.

13. Neville BW, Damm DD, Allen CM, Bouquot JF. Patologia oral e maxilofacial. Rio de Janeiro: Elsevier; 2009.

14. Lunt RC, Law DB. A review of the chronology of eruption of deciduous teeth. J Am Dent Assoc 1974; 89(4):872-9.

15. Diniz MB, Gondim JO, Pansani CA, Abreu-e-Lima FCB. A importância da interação entre odontopediatrias e pediatrias no manejo de dentes natais e neonatais. Rev Paul Pediatr 2008; 26(1):64-9.

16. Sevalho ML, Hanan AS, Alves Filho AO, Medina PO. Dentes natais - relato de caso clínico. Con Scientiae Saúde 2011; 10(1):160-5.

17. Bermúdez ME. Caracterizacion de la cavidad bucal del recien nacido sano y su relacion con el grupo étnico [Dissertação de Mestrado]. Maracaibo: Universidad del Zulia; 2008.

18. Saadia AM. Development of occlusion and oral function in children. Clin Pediatr Dent 1981; 5(2):154-72.

19. Moyers RE, Carlson DS. Maturação da neuromusculatura orofacial. In: Enlow D H. Crescimento facial. São Paulo: Artes Médicas; 1993. p. 260-271.

20. Simpson WJ, Creung DK. Gum pad relationships of infants at birth. J Can Dent Assoc 1973; 39(3):182-8.

21. Corrêa MSNP, Villena SR, Francino VMS. Características da cavidade bucal e da ocorrência de anomalias em recém-nascidos. Rev Paul Odontol 1997; 19(3):34-40.

22. Flinck A, Paludan A, Matsson L, Holm AK, Axelsson I. Oral findings in a group of newborn Swedish children. Pediatr Dent 1994; 4(2):67-73.

23. Albuquerque MES. Estudo da topografia e da morfologia do freio labial superior em crianças de 0 a 36 meses [Dissertação de Mestrado]. São Paulo: Faculdade de Odontologia da Universidade de São Paulo; 1990.

24. Jorgenson RJ, Shapiro SD, Salinas CF, Levin LS. Intraoral findings and anomalies in neonates. Pediatrics 1982; 69(5):577-82.

\section{Endereço para correspondência:}

Dayane Franco Barros Mangueira Leite Cidade Universitária, s/n - Castelo Branco 58051-900, João Pessoa, Paraíba, Brasil Telefone: (83) 3216-7250 E-mail: dayanemangueira@gmail.com

Recebido: 02/01/18. Aceito: 23/02/18. 